\title{
Correction to: An Enhanced Crow Search Inspired Feature Selection Technique for Intrusion Detection Based Wireless Network System
}

\author{
Ashish Khanna ${ }^{1}$ Poonam Rani ${ }^{2}$. Puneet Garg ${ }^{3}$ P Prakash Kumar Singh ${ }^{4}$. \\ Aditya Khamparia ${ }^{5}$ (i)
}

Published online: 23 September 2021

(c) Springer Science+Business Media, LLC, part of Springer Nature 2021

\section{Correction to: Wireless Personal Communications https://doi.org/10.1007/s11277-021-08766-9}

In this article the author name Puneet Garg was incorrectly written as Punnet Garg. The original article has been corrected.

Publisher's Note Springer Nature remains neutral with regard to jurisdictional claims in published maps and institutional affiliations.

The original article can be found online at https://doi.org/10.1007/s11277-021-08766-9.

Aditya Khamparia

aditya.khamparia88@gmail.com

Ashish Khanna

ashishkhanna@mait.ac.in

Poonam Rani

poonam.rani.nsit@gmail.com

Puneet Garg

puneetgarg.er@gmail.com

Prakash Kumar Singh

pks.cse13@gmail.com

1 Department of Computer Science Engineering, Maharaja Agrasen Institute of Technology, New Delhi, India

2 Division of Computer Engineering, Netaji Subhas University of Technology, New Delhi, India

3 J. C. Bose University of Science and Technology, YMCA, Faridabad, Haryana, India

4 Department of Computer Science Engineering, Rajkiya Engineering College Mainpuri, Mainpuri, U. P, India

5 Department of Computer Science, Babasaheb Bhimrao Ambedkar University, Satellite Centre, Amethi, Uttar Pradesh, India 